\title{
Nab-paclitaxel plus gemcitabine in the treatment of metastatic pancreatic cancer: utility and experience from the clinic
}

This article was published in the following Dove Press journal:

Gastrointestinal Cancer: Targets and Therapy

14 January 2016

Number of times this article has been viewed

\section{Madappa N Kundranda \\ Tomislav Dragovich}

Division of Hematology and Oncology, Banner MD Anderson Cancer Center, Gilbert, AZ, USA
Correspondence: Madappa N Kundranda Division of Hematology and Oncology, Banner MD Anderson Cancer Center, 2946 E Banner Gateway Drive, Gilbert, AZ 85234, USA

Tel +I 4802563623

Fax +I 4802564003

Email madappa.kundranda@bannerhealth. com
Abstract: Pancreatic ductal adenocarcinoma remains one of the deadliest epithelial cancers, primarily due to late diagnosis, early metastasis and the lack of effective treatments. With recent advances in systemic therapies, the median survival for metastatic disease has essentially doubled to approximately 1 year, and a significant number of patients are receiving multiple lines of therapy. One such first-line therapy is the combination of gemcitabine with nab-paclitaxel, which was approved by the US Food and Drug Administration in 2013. This standard option is now serving as a backbone to other novel combinations. In this review, we focus on the development of this combination, its clinical utility, and real-life experiences of managing patients with metastatic pancreatic ductal adenocarcinoma receiving gemcitabine and nab-paclitaxel.

Keywords: pancreatic ductal adenocarcinoma, nab-paclitaxel, MPACT trial, PRODIGE 4/ ACCORD 11 trial

\section{Introduction}

Pancreatic ductal adenocarcinoma (PDAC) is a deadly disease with a 5-year survival of less than $5 \% .{ }^{1}$ At diagnosis, only $10 \%-20 \%$ of patients are considered candidates for a curative resection. ${ }^{2}$ The large majority of patients have metastatic disease and a median overall survival (mOS) ranging from 3 to 6 months. ${ }^{3}$ Gemcitabine, a nucleoside analog with a similar structure to cytarabine, was noted in initial studies to have an objective response rate in chemotherapy-naïve patients when administered as a single agent. ${ }^{4}$ This led to the seminal study by Burris et $\mathrm{al}^{5}$ in 1997 , evaluating clinical benefit and survival in 126 previously untreated patients with locally advanced or metastatic pancreatic cancer who were randomly assigned to 5 -fluorouracil (5-FU) $\left(600 \mathrm{mg} / \mathrm{m}^{2}\right.$ weekly) or gemcitabine $\left(800 \mathrm{mg} / \mathrm{m}^{2}\right.$ intravenous weekly for 3 of every 4 weeks). "Clinical benefit index" was defined as a composite measure consisting of reduction of pain, intake of analgesic drugs, and weight loss without deterioration in any other factors. There were no confirmed objective responses in either group. However, gemcitabine was associated with significantly better clinical response (24\% vs 5\%), mOS (5.6 vs 4.4 months), and 1-year survival (18\% vs $2 \%$ ). Based upon these data, gemcitabine was approved for first-line therapy of metastatic pancreatic cancer.

Given the modest and disappointing impact on OS achieved with the single agent gemcitabine, other agents have been tested in advanced pancreatic cancer. Despite higher objective response rates in some studies, 33 randomized Phase III trials failed to demonstrate a survival benefit, with the exception of erlotinib, until 2011 when FOLFIRINOX was introduced for front-line therapy in advanced PDAC. ${ }^{6}$ 
Erlotinib is a small-molecule tyrosine kinase inhibitor of the epidermal growth factor receptor. The pivotal Phase III trial was conducted by the National Cancer Institute of Canada Clinical Trials Group (NCIC CTG) and it randomized patients to receive erlotinib in combination with gemcitabine or to gemcitabine alone. The difference in mOS between the erlotinib and placebo groups was modest (6.24 vs 5.91 months), with a significant decrement in the hazard ratio (HR) for death of 0.82 (95\% confidence interval [CI], $0.69-0.99 ; P=0.04)$ and a significant improvement in 1-year survival rate $(23 \%$ vs $17 \%, P=0.02) .{ }^{7}$ Based on the NCIC CTG trial results, the US Food and Drug Administration (FDA) and the European Medicines Evaluation Agency have approved the combination of erlotinib and gemcitabine for first-line treatment of advanced pancreatic cancer. However, the modest survival benefit with added cost and toxicity has led to limited utilization of erlotinib in clinical practice.

\section{Development of gemcitabine-nab- paclitaxel in pancreatic cancer Nab-paclitaxel}

Albumin-bound paclitaxel (nab-paclitaxel) is a solvent-free formulation of paclitaxel that was initially developed to overcome toxicities associated with the solvents used in the formulation of standard paclitaxel and to potentially improve efficacy. It received FDA approval for the treatment of metastatic breast cancer in 2005, followed by approval for treatment of locally advanced or metastatic non-small-cell lung cancer in 2012.

Nab-paclitaxel is a solvent-free albumin bound form that has been noted to have several advantages including delivering significantly higher doses of paclitaxel over a shorter infusion time. ${ }^{8}$ Although the precise mechanism is unknown, it has been postulated that the combination of nab-paclitaxel with albumin uses endogenous albumin transport pathways, including receptor-mediated transcytosis, to cross endothelial cell monolayers and enter tumors. ${ }^{8,9}$ When this was evaluated in a preclinical study, nab-paclitaxel was transported across endothelial cells 4-fold more compared with solvent-based paclitaxel. ${ }^{8}$ In addition, it was noted that Kolliphor EL inhibited the binding of paclitaxel to albumin and endothelial cells, thereby limiting intratumoral uptake of paclitaxel. ${ }^{8}$

In a recent meta-analysis on the population pharmacokinetics and pharmacodynamics, pharmacologic features of nab-paclitaxel appear to be distinct from those of solventbased paclitaxel. ${ }^{10}$ These differences can contribute to the differences in clinical safety and efficacy between the two paclitaxel formulations.
In addition, there is emerging data in animal models which indicate that nab-paclitaxel increases the intratumor concentration of gemcitabine by inactivating cytidine deaminase, an enzyme involved in the catabolism of gemcitabine. ${ }^{11}$ This led to a clinical study of 16 patients with operable PDAC who were treated with gemcitabine and nab-paclitaxel. Stromal remodeling with marked alteration of collagen architecture was noted in a majority of patients. ${ }^{12}$ Although unclear at the current time, it certainly raises the possibility of nab-paclitaxel having an antistromal effect independent of gemcitabine.

\section{Early development}

In preclinical studies, it was noted that PDAC tumor samples overexpressing secreted protein acidic and rich in cysteine (SPARC), an albumin-binding protein, were more responsive to antitumor activity of nab-paclitaxel. ${ }^{13-16}$

Based on the aforementioned preclinical studies, nab-paclitaxel was selected as a combination partner for gemcitabine. In a Phase I/II trial, the maximum tolerated dose of nab-paclitaxel in combination with gemcitabine was established at $125 \mathrm{mg} / \mathrm{m}^{2}$ weekly on a $3 / 4$ week schedule in patients with advanced PDAC. Dose-limiting toxicities were sepsis and neutropenia. For patients treated at the maximum tolerated dose $(n=44)$, overall response rate (ORR) was $48 \%$, and $\mathrm{mOS}$ was 12.2 months. A significant increase in OS was observed for patients in the high-SPARC group compared with patients in the low-SPARC group (mOS, 17.8 vs 8.1 months, respectively; $P=0.0431$ ). In addition, SPARC level remained a significant predictor for OS in a multivariate Cox regression model after adjusting for confounders. ${ }^{17}$

Thus, the nab-paclitaxel plus gemcitabine regimen was carried forward into a Phase III trial (MPACT trial).

\section{MPACT study}

This is the largest Phase III trial that has been conducted in pancreatic ductal carcinoma, with more than 850 patients enrolled worldwide, comparing $125 \mathrm{mg} / \mathrm{m}^{2}$ nab-paclitaxel plus $1,000 \mathrm{mg} / \mathrm{m}^{2}$ of gemcitabine (weekly for $3 / 4$ weeks) to gemcitabine alone. ${ }^{18}$ The mOS (primary endpoint) was significantly longer with nab-paclitaxel plus gemcitabine vs gemcitabine alone ( 8.5 vs 6.7 months; $P<0.001)$. Among the regional cohorts, a statistically significant difference in mOS was only observed among patients from North America and Australia; however, the trend remained in favor of nab-paclitaxel plus gemcitabine vs gemcitabine alone among patients from Europe. ${ }^{19}$ The treatment benefit of nab-paclitaxel plus gemcitabine over gemcitabine alone 
was consistent across most prespecified subgroups, including those patients with more advanced disease (eg, poorer performance status, liver metastasis, $\geq 3$ sites of metastatic disease, and carbohydrate antigen 19-9 levels $59 \times$ upper limit of normal). Grade $\geq 3$ neutropenia ( $38 \%$ vs $27 \%$ ), fatigue $(17 \%$ vs $7 \%)$, and neuropathy (17\% vs $1 \%)$ were higher with nab-paclitaxel plus gemcitabine vs gemcitabine alone; it should be noted that no patients experienced grade 4 neuropathy in either arm. As observed in other trials, ${ }^{15,16,20}$ the grade 3 neuropathy associated with nab-paclitaxel resolved for a majority of patients and improved to grade 1 or lower in a median of 29 days.

Based on the early-phase data indicating that SPARC was a significant predictor for the OS, its association was evaluated in this Phase III study. SPARC was measured in the tumor stroma of 256 patients $(30 \%)$, the tumor epithelia of 301 patients $(35 \%)$, and plasma of 343 patients $(40 \%)$. For all patients, stromal SPARC level (high [n=71] vs low $[\mathrm{n}=185])$ was not associated with $\mathrm{OS}(\mathrm{HR}=1.019 ; P=0.903)$. In addition, there was no association observed between stromal SPARC level and OS in either treatment arm. ${ }^{21}$

Based on the clinical results, nab-paclitaxel plus gemcitabine became an FDA-approved regimen for the first-line treatment of patients with metastatic pancreatic cancer in September 2013.

\section{Clinical utility of nab-paclitaxel plus gemcitabine}

The clinical utility of a combination chemotherapy regimen is not only dependent on efficacy but also on other factors including toxicities, availability of alternate therapies, and convenience of delivery. The alternate therapies available include the following:

1. gemcitabine monotherapy

2. gemcitabine plus erlotinib

3. gemcitabine plus nab-paclitaxel

4. FOLFIRINOX.

Gemcitabine monotherapy is still a reasonable choice in a subset of patients who may not tolerate combination therapy. Gemcitabine therapy has modest objective response rate and impact on survival, which are less compared with combination regimen. However, this could be an excellent choice for patients with borderline performance status (PS) and poor liver function. Despite modest efficacy, gemcitabine therapy offers meaningful clinical benefit to patients, as reported in the original trial (Clinical Benefit Index). ${ }^{5}$ As described, gemcitabine-erlotinib, although FDA-approved, has not gained much popularity in routine, real-life clini- cal practice. While providing some modest efficacy, added fatigue, anorexia, and skin rash are often not viewed favorably by both patients and physicians. Interestingly, the approved dose of erlotinib in this setting is lower than erlotinib dose approved for lung cancer even though the Phase IB trial of gemcitabine and erlotinib suggested that the full dose of erlotinib can be combined with gemcitabine resulting in a promising progression-free survival (PFS) and OS in patients with pancreatic cancer. ${ }^{22}$

\section{FOLFIRINOX (PRODIGE 4/ ACCORD I I trial)}

FOLFIRINOX is an effective front-line treatment regimen (folinic acid $400 \mathrm{mg} / \mathrm{m}^{2}, 5-\mathrm{FU}$ bolus $400 \mathrm{mg} / \mathrm{m}^{2}$ followed by 46-hour infusional 5-FU 2,400 mg/m², irinotecan $180 \mathrm{mg}$ / $\mathrm{m}^{2}$, and oxaliplatin $85 \mathrm{mg} / \mathrm{m}^{2}$ ) for patients with metastatic pancreatic cancer. The rationale for this combination was based on a Phase II trial which demonstrated a 26\% response rate and a mOS of 10.2 months. ${ }^{23}$ Of the 46 patients treated on the trial (including nonmetastatic disease), grade $3 / 4$ neutropenia occurred in $52 \%$ of patients, including two patients with febrile neutropenia. The response rate was 26\% (95\% CI, 13\%-39\%), and median time-to-progression was 8.2 months (95\% CI, 5.3-11.6 months), and mOS was 10.2 months (95\% CI, 8.1-14.4 months). Based on this and the fact that toxicity, although significant, was reported as being manageable, investigators of the PRODIGE Intergroup designed a randomized Phase II/III clinical trial comparing FOLFIRINOX to single-agent gemcitabine as first-line treatment for metastatic PDAC. ${ }^{6}$

This was a multicenter study of 342 patients with histologically confirmed metastatic disease with an Eastern Cooperative Oncology Group performance status $0-1$. The primary endpoint was OS; secondary endpoints were PFS, tumor response (RECIST), safety, and quality of life (QoL). The study was closed early when an interim analysis showed a statistically significant 4.3 months prolongation in $\mathrm{mOS}$ favoring FOLFIRINOX (11.1 vs 6.8 months; $\mathrm{HR}=0.57, P<0.001$ ). Median PFS was 6.4 vs 3.3 months $(P<0.001)$ and ORR was $31 \%$ vs $9.5 \%(P<0.001)$. It should also be noted that there was a significant increase in grades 3-4 toxicities mainly related to cytopenias, neutropenic fever, diarrhea, vomiting, and peripheral neuropathy (all with $P<0.01$ ) in the experimental arm.

Based on all of the above data in a "real world" setting, the front-line options for a majority of patients with metastatic pancreatic adenocarcinoma are either gemcitabine plus nab-paclitaxel or FOLFIRINOX. Unfortunately, there is no randomized trial comparing the two regimens head to head 
and hence the significant limitations with cross-trial comparison should be acknowledged.

\section{Toxicity profile}

\section{Gemcitabine plus nab-paclitaxel}

The eligibility criteria for this trial included older patients $(>75)$ and patients with an Eastern Cooperative Oncology Group performance status of 2 . In addition, the trial was conducted at both academic centers and in community practice. $^{18}$

The significant toxicities during the trial were reported as grade $\geq 3$ neutropenia ( $38 \%$ vs $27 \%$ ), fatigue ( $17 \%$ vs $7 \%$ ), and neuropathy (17\% vs 1\%), which were higher with nabpaclitaxel plus gemcitabine vs gemcitabine alone. During the trial, grade 3 neuropathy associated with nab-paclitaxel resolved for a majority of patients and improved to grade 1 or lower in a median of 29 days.

In clinical practice, the toxicities vary based on the line of therapy and the presence of baseline toxicities including the underlying neuropathy either from previous oxaliplatin use or from diabetes. The hematological toxicities that tend to prevent maintaining dose intensity or necessitating dose reductions include both neutropenia and thrombocytopenia.

A retrospective study of 47 patients evaluated for response with a dose modification in the regimen (gemcitabine $1,000 \mathrm{mg} / \mathrm{m}^{2}$ and nab-paclitaxel $125 \mathrm{mg} / \mathrm{m}^{2}$ every 2 weeks) demonstrated a mOS of 11.1 months and less severe (grade 3 or 4$)$ neutropenia (10\%) and peripheral neuropathy (2\%) than seen with the original regimen. ${ }^{24}$ A prospective singlearm Phase II study was terminated early without published results (ClinicalTrials.gov identifier: NCT01851174). Dose modifications of the standard dosing are very pertinent in elderly patients, patients with liver dysfunction, or patients who may be receiving gemcitabine + nab-paclitaxel in a second-line setting (after being already exposed to FOLFIRINOX). In this setting, cumulative bone marrow toxicity (thrombocytopenia) and neurotoxicity may require dose and schedule adjustments.

\section{Comparison to FOLFIRINOX regimen}

The strict eligibility criteria of the PRODIGE 4/ACCORD 11 trial (which was mainly conducted at academic institutions) along with the tolerability and impact on QoL are the main concerns that have arisen regarding the general application and usage of this regimen. In PRODIGE 4/ACCORD 11 trial, ${ }^{25}$ the authors compared the QoL impairment in patients and determined that FOLFIRINOX significantly reduces QoL impairment compared with gemcitabine.
In comparison, patients enrolled in MPACT trial had somewhat lower PS and age limit was also not set. It is possible that higher efficacy seen in PRODIGE 4/ACCORD 11 can be accounted for by patients' selection bias. However, the impact of gemcitabine plus nab-paclitaxel on QoL was not recorded in MPACT trial.

A population-based retrospective study of 100 consecutive pancreatic cancer patients was undertaken to determine the ability to utilize the entry criteria of the PRODIGE 4/ ACCORD 11 trial in the "real world" setting. ${ }^{26}$ The authors found that only 26 patients would have been eligible, with the main reasons for exclusion being older age (22\%), poor performance status (64\%), and organ dysfunction $(28 \%)$. This reflects the current clinical practice, at least in North America, where the majority of the patients are unable to receive FOLFIRINOX due to the aforementioned factors.

In addition, the patients who receive FOLFIRINOX in palliative setting are often initiated at a lower dose. In a small retrospective study of 28 patients, the efficacy and tolerability of a modified version of FOLFIRINOX by removing the bolus 5-FU and adding the routine use of growth factor prophylaxis were evaluated. Although it demonstrated easily manageable side effects with a short median follow-up of 5.5 months, OS or PFS was not reached. ${ }^{27}$ The concern with this practice is that while this could help with improved tolerability and compliance, these empiric dose modifications can certainly impact efficacy and survival.

\section{Gemcitabine plus nab-paclitaxel as a backbone for novel therapies}

Even with recent advances in systemic therapies, the overall prognosis in metastatic PDAC is dismal, hence necessitating the need to develop newer and more effective therapies. Currently, there are more than 20 open clinical trials using this backbone (Table 1). Some promising novel combinations will now be discussed.

\section{PEGPH20}

A histological hallmark of PDAC is the dense stroma surrounding malignant epithelial cells. The desmoplastic stroma evolves during disease progression and consists of both cellular and acellular components. The cellular component comprises of endothelial cells, fibroblasts, stellate cells, immune cells, and nerve cells. The acellular component comprises of collagen, fibrinogen, hyaluronan (HA), and fibrin, in addition to growth factors and proteins. ${ }^{28}$ Activated stromal fibroblasts, or myofibroblasts, produce matrix constituents that alter not just the physical structure of the developing 
Table I Novel combinations using the gemcitabine/nab-paclitaxel backbone that are in various stages of testing in the clinic

\begin{tabular}{|c|c|c|c|c|}
\hline $\begin{array}{l}\text { Clinical trial } \\
\text { ID }\end{array}$ & Title of trial & Novel agent & Phase & Opened \\
\hline NCT0I934634 & $\begin{array}{l}\text { Phase I trial of the proapoptotic agonist, LCLI6I, and gemcitabine plus nab- } \\
\text { paclitaxel in patients with metastatic pancreatic cancer }\end{array}$ & LCL-I6I & 1 & March I, 20I4 \\
\hline NCT02050I78 & $\begin{array}{l}\text { A Phase IB dose escalation study of OMP-54F28 in combination with nab- } \\
\text { paclitaxel and gemcitabine in patients with previously untreated stage IV } \\
\text { pancreatic cancer }\end{array}$ & Ipafricept & I & January 13,2014 \\
\hline NCT020053I5 & $\begin{array}{l}\text { A Phase IB dose escalation study of vantictumab (OMP-I8R5) in combination } \\
\text { with nab-paclitaxel and gemcitabine in patients with previously untreated } \\
\text { stage IV pancreatic cancer }\end{array}$ & Vantictumab & 1 & $\begin{array}{l}\text { December } 4 \text {, } \\
2013\end{array}$ \\
\hline NCT02047500 & $\begin{array}{l}\text { An open-label, Phase I dose escalation trial of TH-302 in combination with } \\
\text { gemcitabine and nab-paclitaxel in previously untreated subjects with metastatic } \\
\text { or locally advanced unresectable pancreatic adenocarcinoma }\end{array}$ & Evofosfamide & I & January I, 2014 \\
\hline NCT02I0I580 & $\begin{array}{l}\text { Phase IB trial of ADI-PEG } 20 \text { plus nab-paclitaxel and gemcitabine in subjects } \\
\text { with advanced pancreatic cancer }\end{array}$ & Pegargiminase & 1 & $\begin{array}{l}\text { December 3, } \\
2014\end{array}$ \\
\hline NCT02। 38383 & $\begin{array}{l}\text { A Phase I trial with cohort expansion of enzalutamide in combination with } \\
\text { gemcitabine and nab-paclitaxel for the treatment of advanced pancreatic cancer }\end{array}$ & Enzalutamide & 1 & May I, 2014 \\
\hline NCT02227940 & $\begin{array}{l}\text { A Phase I study of ceritinib (LDK378), a novel ALK inhibitor, in combination } \\
\text { with gemcitabine-based chemotherapy in patients with advanced solid tumors }\end{array}$ & Ceritinib & I & January I, 2015 \\
\hline NCT0223I723 & $\begin{array}{l}\text { A Phase IB clinical study of BBI608 in combination with gemcitabine and } \\
\text { nab-paclitaxel in adult patients with metastatic pancreatic adenocarcinoma }\end{array}$ & BBI-608 & I & August I, 2014 \\
\hline NCT02399I37 & $\begin{array}{l}\text { A randomized, double-blind, placebo-controlled Phase II study of MM- I4I } \\
\text { plus nab-paclitaxel and gemcitabine versus nab-paclitaxel and gemcitabine } \\
\text { in front-line metastatic pancreatic cancer }\end{array}$ & MM-I4I & II & May 5, 2015 \\
\hline NCT02340II7 & $\begin{array}{l}\text { Phase II study of combined targeted p } 53 \text { gene therapy (SGT-53) plus } \\
\text { gemcitabine/nab-paclitaxel for treatment of metastatic pancreatic cancer }\end{array}$ & SGT-53 & ॥ & January I, 2015 \\
\hline NCT02I0I02I & $\begin{array}{l}\text { A Phase II, randomized, double-blind study of gemcitabine and nab-paclitaxel } \\
\text { combined with momelotinib in subjects with previously untreated metastatic } \\
\text { pancreatic ductal adenocarcinoma preceded by a dose-finding, lead-in phase }\end{array}$ & Momelotinib & II & June I, 2014 \\
\hline NCT02I 24317 & $\begin{array}{l}\text { Phase II trial of nab-paclitaxel plus S-I in first-line treatment of patients with } \\
\text { advanced pancreatic cancer }\end{array}$ & TS-I & II & April I, 2014 \\
\hline NCT0207788I & $\begin{array}{l}\text { A Phase } 1 / / l \text { study of indoximod in combination with gemcitabine and } \\
\text { nab-paclitaxel in patients with metastatic adenocarcinoma of the pancreas }\end{array}$ & Indoximod & $\mathrm{I} / \mathrm{II}$ & August I, 2014 \\
\hline NCT0I62I 243 & $\begin{array}{l}\text { A Phase I/II, two-part, multicenter study to evaluate the safety and efficacy } \\
\text { of M402 in combination with nab-paclitaxel and gemcitabine in patients with } \\
\text { metastatic pancreatic cancer }\end{array}$ & Necuparanib & $\mathrm{I} / \mathrm{II}$ & April I, 2012 \\
\hline NCTOI506973 & $\begin{array}{l}\text { A Phase I/II/pharmacodynamic study of hydroxychloroquine in combination } \\
\text { with gemcitabine/abraxane to inhibit autophagy in pancreatic cancer }\end{array}$ & Hydroxychloroquine & $\mathrm{I} / \mathrm{II}$ & $\begin{array}{l}\text { December I, } \\
2011\end{array}$ \\
\hline NCT0I647828 & $\begin{array}{l}\text { A Phase IB/II study of OMP-59R5 in combination with nab-paclitaxel and } \\
\text { gemcitabine in subjects with previously untreated stage IV pancreatic cancer } \\
\text { (Antibody therapy in first-Line Pancreatic cancer Investigating anti-Notch } \\
\text { Efficacy and safety [ALPINE]) }\end{array}$ & Tarextumab & $\mathrm{I} / \mathrm{II}$ & $\begin{array}{l}\text { October } 4, \\
2012\end{array}$ \\
\hline NCT0I0888I5 & $\begin{array}{l}\text { A Phase II study of gemcitabine and nab-paclitaxel in combination with } \\
\text { GDC-0449 (Hedgehog inhibitor) in patients with previously untreated } \\
\text { metastatic adenocarcinoma of the pancreas }\end{array}$ & Vismodegib & II & $\begin{array}{l}\text { September I, } \\
2010\end{array}$ \\
\hline NCT0I46I9I5 & $\begin{array}{l}\text { A randomized Phase II open-label study to assess the efficacy and safety of } \\
\text { gemcitabine }+ \text { abraxane with or without ODSH (2-0, 3-0 desulfated heparin) } \\
\text { as first line treatment of metastatic pancreatic cancer }\end{array}$ & PGX-100 & II & $\begin{array}{l}\text { November I, } \\
201 \mathrm{I}\end{array}$ \\
\hline NCT02358I6I & $\begin{array}{l}\text { Phase } \mathrm{I} / / \mathrm{l} \text { study of LDE225 in combination with gemcitabine and nab-paclitaxel } \\
\text { in patients with locally advanced or metastasized pancreatic cancer }\end{array}$ & Erismodegib & $\mathrm{I} / \mathrm{II}$ & March 12, 2013 \\
\hline NCT02I 09445 & $\begin{array}{l}\text { Phase I/II study of Pf-030840 I } 4 \text { in combination with gemcitabine and } \\
\text { nab-paclitaxel in patients with previously untreated metastatic pancreatic } \\
\text { ductal adenocarcinoma }\end{array}$ & PF-30840I4 & $\mathrm{I} / \mathrm{II}$ & $\begin{array}{l}\text { September I, } \\
2014\end{array}$ \\
\hline NCT02I 78436 & $\begin{array}{l}\text { A Phase IB/II study of the selective inhibitor of nuclear export (SINE) KPT-330, } \\
\text { gemcitabine and nab-paclitaxel in patients with metastatic pancreatic cancer }\end{array}$ & Selinexor & $\mathrm{I} / \mathrm{II}$ & $\begin{array}{l}\text { October I, } \\
2014\end{array}$ \\
\hline NCT0I839487 & $\begin{array}{l}\text { A Phase II, randomized, multicenter study of PEGPH20 (PEGylated } \\
\text { recombinant human hyaluronidase) combined with nab-paclitaxel plus } \\
\text { gemcitabine compared with nab-paclitaxel plus gemcitabine in subjects with } \\
\text { stage IV previously untreated pancreatic cancer }\end{array}$ & PEGPH20 & II & April 23, 2013 \\
\hline
\end{tabular}


tumor but also modulate tumor cell behavior through direct binding interactions with surface receptors. Hence, the stroma can serve as a formidable barrier to prevent effective drug delivery resulting in stromal resistance. ${ }^{29}$ Thus by gaining better understanding of the mechanism(s), it is conceivable to develop potential therapeutic strategies to target the stroma with novel anticancer agents. One such therapeutic strategy is PEGylated recombinant human hyaluronidase (PEGPH20).

HA is a large, linear, negatively charged soluble macromolecule that plays a vital role in maintaining the architectural integrity of the cell and is overexpressed in $>80 \%$ of pancreatic cancers. ${ }^{30} \mathrm{HA}$ also binds to the surface receptors and can promote cell survival, proliferation, and invasion, thus playing a key role in tumorigenesis. Tumors that accumulate HA develop high interstitial fluid pressure and drug resistance. ${ }^{31}$ In the mammalian system, the HA levels are maintained by an intricate play of selective expression and activity of three different synthases, HAS1-3, and six different hyaluronidases. ${ }^{32}$ Although the recombinant form of human hyaluronidase (PH20) possesses an extremely short circulatory half-life $\left(t_{1 / 2}<3\right.$ minutes $)$, conjugation with polyethylene glycol (PEGPH20) preserves enzymatic activity and extends the half-life to $>10$ hours. ${ }^{29}$ In a preclinical randomized placebo-controlled trial using a mouse model, PEGPH20 when combined with gemcitabine significantly increased objective response rate, decreased metastatic tumor burden, and prolonged median survival as opposed to gemcitabine alone. ${ }^{29}$

In a Phase IB study of advanced untreated stage IV pancreatic ductal adenocarcinoma, 28 patients were treated with 1 of 3 doses of PEGPH20 (1.0, 1.6, or $3.0 \mu \mathrm{g} / \mathrm{kg})$ twice weekly for 4 weeks, and weekly thereafter, in combination with gemcitabine $1,000 \mathrm{mg} / \mathrm{m}^{2}$ administered intravenously once a week for weeks $1-7$, followed by 1 week of rest.

Preliminary results demonstrated an ORR of $42 \%$ (95\% CI, 22\%-62\%) with gemcitabine plus PEGPH20 at doses of 1.6 and $3.0 \mu \mathrm{g} / \mathrm{kg}$. Furthermore, in the subset of patients with high expression of HA, the RR was $64 \% .{ }^{33}$ Of note, there were thromboembolic events reported in $28.6 \%$ of patients in the study.

The Phase II study evaluating PEGPH20 in combination with gemcitabine/abraxane or gemcitabine (NCT01839487) had been placed on temporary hold, which was subsequently lifted by the FDA and underwent revision of protocol to include evaluation for thromboembolic events and prophylactic low-molecular-weight heparin to prevent thromboembolism.

\section{JAK/STAT pathway inhibition}

The role of inflammation in pancreatic cancer is evident, but the precise mechanism is not well understood. Inflammatory states are characterized by the creation of reactive oxygen species and the induction of cell cycling for tissue growth and repair. The risk factors (including obesity, cigarette smoking, type 2 diabetes, and pancreatitis) in the development of pancreatic cancer are linked to inflammation which is the key driver of its pathology. ${ }^{34}$ In addition, increase in inflammatory markers is associated with poor prognosis in patients receiving systemic therapy for advanced pancreatic cancer. ${ }^{35}$ The C-reactive protein (CRP) is a marker of systemic inflammation that is produced by proinflammatory cytokines, including interleukin (IL)-1b, IL-6, IL-8, and tumor necrosis factor (TNF- $\alpha$ ), via the transcription factor nuclear factor- $\kappa B$ $(\mathrm{NF}-\kappa \mathrm{B})$ and the activation of the signal transducer and activator of transcription 3 (STAT3) protein. ${ }^{35}$ The increase of proinflammatory cytokines is believed to attenuate the benefits of chemotherapy and result in a poor outcome.

Ruxolitinib is a Janus kinase (JAK) inhibitor that suppresses STAT3 phosphorylation and has shown clinical benefits in myelofibrosis. ${ }^{36}$ The RECAP Phase II clinical study randomized 127 patients who had progressed on gemcitabine to capecitabine $\left(1,000 \mathrm{mg} / \mathrm{m}^{2}\right.$ twice daily; D1-14) +/- ruxolitinib (15 mg BID; D1-21) during a 21-day cycle. Although the ORR was $7.8 \%$ for the ruxolitinib arm, a prespecified subgroup of patients with elevated serum CRP $(>13 \mathrm{mg} / \mathrm{L})$ had a statistically significant OS favoring ruxolitinib $(\mathrm{HR}=0.47 ; 95 \% \mathrm{CI}, 0.26-0.85 ; P=0.01)$. In this subgroup, 3- and 6-month survival rates were $48 \%$ and $42 \%$ with ruxolitinib vs $29 \%$ and $11 \%$ with placebo, respectively. However, in the overall patient population the addition of ruxolitnib to capecitabine did not demonstrate a statistically significant survival advantage ( $\mathrm{HR}=0.79 ; 95 \%$ CI, 0.53-1.18). ${ }^{37}$

Currently a second JAK/STAT pathway inhibitor, momelotinib, is being evaluated in a Phase III, randomized, double-blind, placebo-controlled trial with gemcitabine plus nab-paclitaxel (ClinicalTrials.gov Identifier: NCT 02101021).

\section{Conclusion}

A combination of gemcitabine plus nab-paclitaxel adds to the spectrum of currently available treatment options for patients with metastatic pancreatic adenocarcinoma. This combination is also currently being evaluated in adjuvant setting in a Phase III APACT trial comparing this combination vs gemcitabine alone for patients with resected pancreatic adenocarcinomas (ClinicalTrials.gov Identifier: NCT 01964430). 
Based on the current prospective evidence, gemcitabine plus nab-paclitaxel represents an effective and well-tolerated choice for majority of patients who present with metastatic disease. A thoughtful clinician is always facing the task of balancing objective endpoints such as response rate and PFS with subjective factors (but not less meaningful ones) such as QoL and quality time for patients with this incurable disease. The good news is that a physician now has an array of options ranging from higher antitumor activity and higher toxicity index (FOLFIRINOX) to lower intensity and better tolerability options (gemcitabine monotherapy as an example). This certainly allows for customizing and personalizing treatment based on the patient's prognosis, performance status, organ function, and also personal and cultural preferences.

\section{Disclosure}

MNK has received consulting fees for advisory board participation from Celgene and Bayer and for lectures from Celgene. TD has received research support from Halozyme and Lilly. The authors report no other conflicts of interest in this work.

\section{References}

1. Siegel R, Naishadham D, Jemal A. Cancer statistics, 2013. CA: Cancer J Clin. 2013;63(1):11-30.

2. Li D, Xie K, Wolff R, Abbruzzese JL. Pancreatic cancer. Lancet. 2004;363(9414):1049-1057.

3. Sener SF, Fremgen A, Menck HR, Winchester DP. Pancreatic cancer: a report of treatment and survival trends for 100,313 patients diagnosed from 1985-1995, using the National Cancer Database. J Am Coll Surg. 1999;189(1):1-7.

4. Casper ES, Green MR, Kelsen DP, et al. Phase II trial of gemcitabine (2,2'-difluorodeoxycytidine) in patients with adenocarcinoma of the pancreas. Invest New Drugs. 1994;12(1):29-34.

5. Burris HA 3rd, Moore MJ, Andersen J, et al. Improvements in survival and clinical benefit with gemcitabine as first-line therapy for patients with advanced pancreas cancer: a randomized trial. J Clin Oncol. 1997; 15(6):2403-2413.

6. Conroy T, Desseigne F, Ychou M, et al. FOLFIRINOX versus gemcitabine for metastatic pancreatic cancer. NEng J Med. 2011;364(19): 1817-1825.

7. Moore MJ, Goldstein D, Hamm J, et al. Erlotinib plus gemcitabine compared with gemcitabine alone in patients with advanced pancreatic cancer: a phase III trial of the National Cancer Institute of Canada Clinical Trials Group. J Clin Oncol. 2007;25(15):1960-1966.

8. Desai N, Trieu V, Yao Z, et al. Increased antitumor activity, intratumor paclitaxel concentrations, and endothelial cell transport of cremophorfree, albumin-bound paclitaxel, ABI-007, compared with cremophorbased paclitaxel. Clin Cancer Res. 2006;12(4):1317-1324.

9. Desai N, Trieu V, Damascelli B, Soon-Shiong P. SPARC expression correlates with tumor response to albumin-bound paclitaxel in head and neck cancer patients. Transl Oncol. 2009;2(2):59-64.

10. Chen N, Li Y, Ye Y, Palmisano M, Chopra R, Zhou S. Pharmacokinetics and pharmacodynamics of nab-paclitaxel in patients with solid tumors: disposition kinetics and pharmacology distinct from solvent-based paclitaxel. J Clin Pharmacol. 2014;54(10):1097-1107.
11. Frese KK, Neesse A, Cook N, et al. nab-Paclitaxel potentiates gemcitabine activity by reducing cytidine deaminase levels in a mouse model of pancreatic cancer. Cancer Discovery. 2012;2(3):260-269.

12. Alvarez R, Musteanu M, Garcia-Garcia E, et al. Stromal disrupting effects of nab-paclitaxel in pancreatic cancer. Br J Cancer. 2013;109(4): 926-933.

13. Koukourakis MI, Giatromanolaki A, Brekken RA, et al. Enhanced expression of SPARC/osteonectin in the tumor-associated stroma of non-small cell lung cancer is correlated with markers of hypoxia/ acidity and with poor prognosis of patients. Cancer Res. 2003;63(17): 5376-5380.

14. Watkins G, Douglas-Jones A, Bryce R, Mansel RE, Jiang WG. Increased levels of SPARC (osteonectin) in human breast cancer tissues and its association with clinical outcomes. Prostaglandins Leukot Essent Fatty Acids. 2005;72(4):267-272.

15. Gradishar WJ, Tjulandin S, Davidson N, et al. Phase III trial of nanoparticle albumin-bound paclitaxel compared with polyethylated castor oil-based paclitaxel in women with breast cancer. J Clin Oncol. 2005;23(31):7794-7803.

16. Socinski MA, Bondarenko I, Karaseva NA, et al. Weekly nab-paclitaxel in combination with carboplatin versus solvent-based paclitaxel plus carboplatin as first-line therapy in patients with advanced non-small-cell lung cancer: final results of a phase III trial. J Clin Oncol. 2012;30(17): 2055-2062.

17. Von Hoff DD, Ramanathan RK, Borad MJ, et al. Gemcitabine plus nab-paclitaxel is an active regimen in patients with advanced pancreatic cancer: a phase I/II trial. J Clin Oncol. 2011;29(34):4548-4554.

18. Von Hoff DD, Ervin T, Arena FP, et al. Increased survival in pancreatic cancer with nab-paclitaxel plus gemcitabine. N Eng J Med. 2013; 369(18):1691-1703.

19. Siena S, Lipton L, Letourneau R, Tjulandin SA, Ponce CG, Schwarz M. Regional subanalysis of the phase III MPACT trial: nab-paclitaxel plus gemcitabine vs gemcitabine alone for patients with metastatic pancreatic cancer. Abstract presented at: European Society for Medical Oncology Congress, September 26-30, 2014; Madrid, Spain.

20. Gradishar WJ, Krasnojon D, Cheporov S, et al. Phase II trial of nabpaclitaxel compared with docetaxel as first-line chemotherapy in patients with metastatic breast cancer: final analysis of overall survival. Clin Breast Cancer. 2012;12(5):313-321.

21. Hidalgo M, Plaza C, Musteanu M, et al. SPARC expression did not predict efficacy of nab-paclitaxel plus gemcitabine or gemcitabine alone for metastatic pancreatic cancer in an exploratory analysis of the phase III MPACT trial. Clin Cancer Res. 2015;21(21):4811-4818.

22. Dragovich T, Huberman M, Von Hoff DD, et al. Erlotinib plus gemcitabine in patients with unresectable pancreatic cancer and other solid tumors: phase IB trial. Cancer Chemother Pharmacol. 2007;60(2): 295-303.

23. Conroy T, Paillot B, Francois E, et al. Irinotecan plus oxaliplatin and leucovorin-modulated fluorouracil in advanced pancreatic cancer a Groupe Tumeurs Digestives of the Federation Nationale des Centres de Lutte Contre le Cancer study. J Clin Oncol. 2005;23(6): 1228-1236.

24. Krishna K, Blazer MA, Wei L, et al. Modified gemcitabine and nabpaclitaxel in patients with metastatic pancreatic cancer (MPC): a singleinstitution experience. J Clin Oncol. 2015;33:Suppl 3;abstr 366.

25. Gourgou-Bourgade S, Bascoul-Mollevi C, Desseigne F, et al. Impact of FOLFIRINOX compared with gemcitabine on quality of life in patients with metastatic pancreatic cancer: results from the PRODIGE 4/ACCORD 11 randomized trial. J Clin Oncol. 2013;31(1):23-29.

26. Gill S, Ho MY, Kennecke HF, Renouf DJ, Cheung WY, Lim HJ. Defining eligibility of FOLFIRINOX for first-line metastatic pancreatic adenocarcinoma (MPC) in the province of British Columbia: a population-based retrospective study. J Clin Oncol. 2012;30:Suppl;abstr e14588.

27. Mahaseth H, Kauh JS, Brutcher E, Hawk NN, Kim S, Chen Z, et al. Safety and efficacy of modified FOLFIRINOX in pancreatic cancer: a retrospective experience. J Clin Oncol. 2012;30:Suppl;abstr e14614. 
28. Wilson JS, Pirola RC, Apte MV. Stars and stripes in pancreatic cancer: role of stellate cells and stroma in cancer progression. Front Physiol. 2014;5:52.

29. Provenzano PP, Hingorani SR. Hyaluronan, fluid pressure, and stromal resistance in pancreas cancer. Br J Cancer. 2013;108(1):1-8.

30. Theocharis AD, Tsara ME, Papageorgacopoulou N, Karavias DD, Theocharis DA. Pancreatic carcinoma is characterized by elevated content of hyaluronan and chondroitin sulfate with altered disaccharide composition. Biochim Biophys Acta. 2000;1502(2):201-206.

31. Jacobetz MA, Chan DS, Neesse A, et al. Hyaluronan impairs vascular function and drug delivery in a mouse model of pancreatic cancer. Gut. 2013;62(1):112-120.

32. Toole BP. Hyaluronan: from extracellular glue to pericellular cue. Nat Rev Cancer. 2004;4(7):528-539.

33. Strimpakos AS, Saif MW. Update on phase I studies in advanced pancreatic adenocarcinoma. Hunting in darkness? JOP. 2013;14(4):354-358.
34. Greer JB, Whitcomb DC. Inflammation and pancreatic cancer: an evidence-based review. Curr Opin Pharmacol. 2009;9(4):411-418.

35. Mitsunaga S, Ikeda M, Shimizu S, et al. Serum levels of IL-6 and IL-1beta can predict the efficacy of gemcitabine in patients with advanced pancreatic cancer. Br J Cancer. 2013;108(10):2063-2069.

36. Harrison C, Kiladjian JJ, Al-Ali HK, et al. JAK inhibition with ruxolitinib versus best available therapy for myelofibrosis. $N$ Eng J Med. 2012;366(9):787-798.

37. Hurwitz H, Uppal N, Wagner SA, Bendell JC, Beck JT, Wade S, et al. A randomized double-blind phase 2 study of ruxolitinib (RUX) or placebo (PBO) with capecitabine (CAPE) as second-line therapy in patients (pts) with metastatic pancreatic cancer (mPC). J Clin Oncol. 2014;32(5s).

\section{Publish your work in this journal}

Gastrointestinal Cancer: Targets and Therapy is an international, peer-reviewed, open access journal focusing on gastro-intestinal cancer research, identification of therapeutic targets and the optimal use of preventative and integrated treatment interventions to achieve improved outcomes, enhanced survival and quality of life for the cancer patient. The manuscript management system is completely online and includes a very quick and fair peer-review system. Visit http://www.dovepress.com/testimonials.php to read real quotes from published authors.

Submit your manuscript here: http://www.dovepress.com/gastro-intestinal-cancer-targets-and-therapy-journal 